\title{
Tonic vibration reflex in spasticity, Parkinson's disease, and normal subjects
}

\author{
DAVID BURKE ${ }^{1}$, COLIN J. ANDREWS ${ }^{2}$, AND JAMES W. LANCE \\ From the Division of Neurology, the Prince Henry Hospital, and the School of Medicine, the University of New \\ South Wales, Sydney, Australia
}

SUMMARY The tonic vibration reflex (TVR) has been studied in the quadriceps and triceps surae muscles of 34 spastic, 15 Parkinsonism, and 10 normal subjects. The TVR of spasticity develops rapidly, reaching a plateau level within $2-4 \mathrm{sec}$ of the onset of vibration. The tonic contraction was often preceded by a phasic spike which appeared to be a vibration-induced equivalent of the tendon jerk. The initial phasic spike was usually followed by a silent period, and induced clonus in some patients. No correlation was found between the shape of the TVR and the site of the lesion in the central nervous system. The TVR of normal subjects and patients with Parkinsonism developed slowly, starting some seconds after the onset of vibration, and reaching a plateau level in 20-60 sec. A phasic spike was recorded occasionally in these subjects, but the subsequent tonic contraction followed the usual time course. Muscle stretch increased the quadriceps TVR of all subjects, including those with spasticity in whom the quadriceps stretch reflex decreased with increasing stretch. It is suggested that this difference between the tonic vibration reflex and the tonic stretch reflex arises from the selective activation of spindle primary endings by vibration, while both the primary and the secondary endings are responsive to muscle stretch. The TVR could be potentiated by reinforcement in some subjects. Potentiation outlasted the reinforcing manoeuvre, and was most apparent at short muscle lengths. As muscle stretch increased, thus producing a larger TVR, the degree of potentiation decreased. It is therefore suggested that the effects of reinforcement result at least partially from the activation of the fusimotor system. Since reinforcement potentiated the TVR of patients with spinal spasticity in whom a prominent clasp-knife phenomenon could be demonstrated, it is suggested that the effects of reinforcement are mediated by a descending pathway that traverses the anterior quadrant of the spinal cord.

The tonic reflex evoked by muscle vibration has been studied extensively, both in normal man (Lance, 1965; Eklund and Hagbarth, 1965, 1966, De Gail, Lance, and Neilson, 1966; Hagbarth and Eklund, 1966a; Lance, De Gail, and Neilson, 1966; Rushworth and Young, 1966; Marsden, Meadows, and Hodgson, 1969) and in the cat (Matthews, 1966, 1969; Gillies, Burke, and Lance, 1971a, 1971b). Relatively little attention has been given to this 'tonic vibration reflex' (TVR) in spastic man.

It has been reported that the TVR is usually diminished on the affected side of hemiparetic patients (Hagbarth and Eklund, 1966b; Lance et al., 1966), and absent in patients with transection of the spinal cord (De Gail et al., 1966).

1 Commonwealth Postgraduate Scholar and Adolph Basser Research Fellow in Neurology.

${ }^{2}$ Edwin and Daisy Street Research Fellow in Neurology.
From studies in the cat (Gillies et al., 1971a, 1971b), it appears that the abolition of the TVR by spinal transection is due to severance of the vestibulospinal and pontine reticulospinal pathways in the anterior columns of the spinal cord. Hagbarth and Eklund (1968) reported that muscle vibration often produces a rapidly developing tonic contraction in spastic limbs similar to that found in the experimental animal, rather than the slowly increasing tonic contraction of normal man. To date there have been no reports of systematic studies in man of the differences between the normal TVR and the spastic TVR, and there have been no attempts to correlate changes in the TVR with specific central nervous system lesions.

In the upper limbs of spastic patients, the TVR increases as the vibrated muscle is stretched (Hagbarth and Eklund, 1968). The tonic stretch 
reflexes of the biceps and triceps brachii muscles of spastic man also increase with increasing muscle stretch (Ashby and Burke, 1971), so that the behaviour of the TVR parallels that of the stretch reflex in the upper limb. However, vibration is a selective stimulus for the spindle primary ending, and has little effect on the firing frequency of spindle secondary endings (Brown, Engberg, and Matthews, 1967). In the lower limb of spastic patients the stretch reflexes of extensor muscles are inhibited by increasing muscle length, while flexor stretch reflexes are facilitated, effects arising from spindle secondary endings (Burke, Gillies, and Lance, 1970, 1971; Burke, Andrews, and Ashby, 1971). It has yet to be established whether the TVR resembles the stretch reflex in this respect.

This study was undertaken to analyse further the TVR of spastic man in an attempt to answer these questions, and to contrast the results with those obtained by vibrating muscles of normal subjects and patients with Parkinsonism.

\section{METHODS}

The TVR was studied in 34 spastic patients, 15 patients with Parkinson's disease, and 10 normal subjects. Rigidity and bradykinesia were the main manifestations of Parkinson's disease, the patients having been selected for treatment with L-dopa. None of the patients with Parkinsonism had clinical evidence of an upper motor neurone lesion.

All of the 34 spastic patients had typical velocitydependent hypertonia, and the clasp-knife phenomenon was demonstrable in the quadriceps stretch reflex. Of the 34 patients, four were hemiplegic due to cortical or internal capsular lesions, and three had bilateral spasticity due to brain-stem disease. Eight patients suffered from multiple sclerosis and two from familial spastic paraplegia. Five patients were paraparetic: one each from transverse myelitis, spinal cord angioma, spinal metastases, spinal osteomyelitis, and from arterial insufficiency of the spinal cord. The patient with the angioma was examined on a number of occasions, before and after the development of a complete cord lesion which was confirmed at laminectomy. Twelve patients were quadriplegic after trauma to the cervical spinal cord, the lesion being clinically complete in five patients.

Usually the TVR of the quadriceps femoris muscle was studied, but in some patients the triceps surae muscle was also vibrated. Vibration was applied to the muscle belly or to the muscle tendon using either of two vibrators: an orbital physiotherapy vibrator (Kurt Stoll, Neidlingen: Tech., Germany) which was capable of $50 \mathrm{~Hz}$, or a small cylindrical vibrator (TVR Vibrator V1A-F:A Keydon, Uppsala, Sweden) which was capable of frequencies up to $200 \mathrm{~Hz}$. The baseplate of the physiotherapy vibrator was $z$ applied directly to the muscle belly, or the edge of the $\stackrel{\mathbb{D}}{\subseteq}$ baseplate was applied to the muscle tendon. The cylindrical vibrator was fixed to the limb over the muscle belly or muscle tendon by a rubber strap.

When vibration was applied to the quadriceps muscle, the patient reclined in a semi-supine position $\frac{9}{5}$ with both legs hanging over the edge of the examination couch, flexed at the knee. The force exerted by the TVR of the quadriceps muscle was estimated by $\overrightarrow{\vec{F}}$ a force transducer strapped to the leg immediately $\stackrel{5}{\rightarrow}$ above the ankle. The transducer consisted of a fourarm strain gauge bridge bonded to a rigid metal bar. 흠 The bridge was activated by the DC power supply

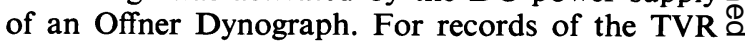
elicited under isometric circumstances, the leg was supported forwards by heavy duty springs at the $\overrightarrow{0}$ ankle, and braced backwards by ties attached to either end of the force transducer. Knee joint position $\vec{\omega}$ was altered by tightening or loosening these ties. $\stackrel{\text { ? }}{\text {. }}$ When the quadriceps muscle was vibrated during a stretching movement, the leg was moved by a handle ${ }_{\dot{\omega}}$ attached to the force transducer. The TVR of the $T$ triceps surae was recorded with the patient in the prone position, and with the leg to be examinefi immobilized in a rigid metal frame, fixed at both ankle 0 and knee. The foot rested against a movable base plate to which a second strain gauge bridge was bond ed.

The electromyogram (EMG) of the relevant musche was recorded by surface electrodes applied $5 \mathrm{~cm}$ apart? over the belly of the muscle. The electrodes wete shielded from the vibrator by a lead earth $10 \times 5 \mathrm{~cm}$ ? in order to reduce vibration-induced artefact. The $?$ position of the knee joint was measured by a gonicmeter. The EMG potentials were monitored on an oscilloscope to ensure that the records were artefactfree, and in some experiments the outputs of the $\stackrel{\unrhd}{\propto}$ force transducer and the goniometer were also $\overrightarrow{\vec{P}}$ monitored. Tension, joint position and EMG were $\frac{9}{3}$ recorded on a four-channel Offner Dynograph. Occasionally the EMG potentials were integrated (time constant $0.2 \mathrm{sec}$ ), and recorded in this form as well.

The effects of reinforcement on the TVR were studied using the Jendrassik manoeuvre. During such 3 . studies subjects were continually exhorted to maxi- $\dot{\delta}$ mum effort in order to produce a constant and reproducible degree of reinforcement.

\section{RESULTS}

TONIC VIBRATION REFLEX A TVR could be elicited from the quadriceps or triceps surae muscles $N$ of all spastic patients except those with clinically N complete spinal cord lesions. As recorded isometrically, the TVR of spastic patients usually ${ }_{0}^{2}$ developed abruptly, reaching a plateau tension $\frac{0}{\Phi}$ 
within 2-4 sec of the onset of vibration (Fig. 1a). An initial phasic spike was often recorded after the onset of vibration, tension then subsiding momentarily before rapidly assuming the plateau level (Fig. 1b). Occasionally a TVR of relatively slow onset could be recorded in spastic limbs (Fig. 1c), but this could usually be altered by

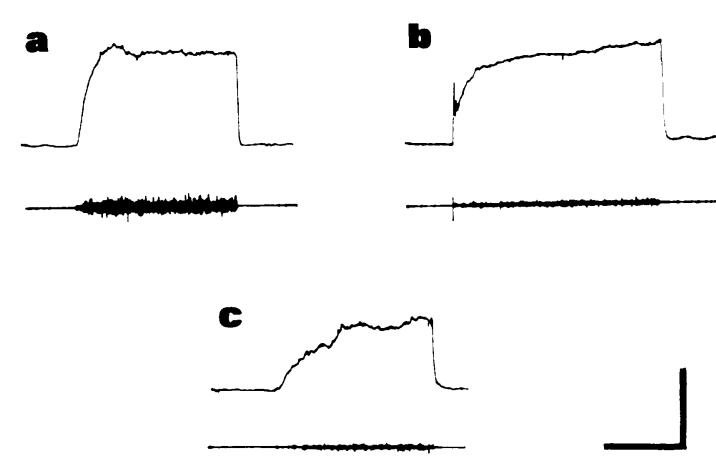

FIG. 1. The TVR of spastic man. The three TVRs shown were all obtained from the same patient. In a, low frequency vibration was applied to the muscle tendon, in $\mathrm{b}$ high frequencyvibration was applied to the tendon, and in c low frequency vibration was applied to the muscle belly. Calibrations: vertical-4 Kg, $1 \mathrm{mV}$ for a; $2 \mathrm{mV}$ for $\mathrm{b}$ and $\mathrm{c}$; horizontal-10 sec.

reinforcement, or by changing the frequency of vibration or the site of application of the vibrator to the limb. The tension produced by the TVR was generally well maintained during continued vibration (up to five minutes of recording), and did not decline to less than $30 \%$ of its initial value. The EMG response to the onset of vibration usually showed an initial phasic burst of potentials after a latency of 50 to $100 \mathrm{msec}$, and this was often accompanied by a phasic spike of tension, as seen in Fig. 1b. There was then a momentary pause in EMG activity for 100 to $150 \mathrm{msec}$ before the tonic EMG response started. On cessation of vibration EMG and reflex tension decreased rapidly after a delay of up to $0.5 \mathrm{sec}$.

The TVR of patients with Parkinsonism did not differ significantly from that of normal subjects in whom a recordable tonic contraction started some seconds after the onset of vibration and then increased slowly over 20 to $60 \mathrm{sec}$ (Fig. 2). The rising phase usually became more rapid if the frequency of vibration was increased.

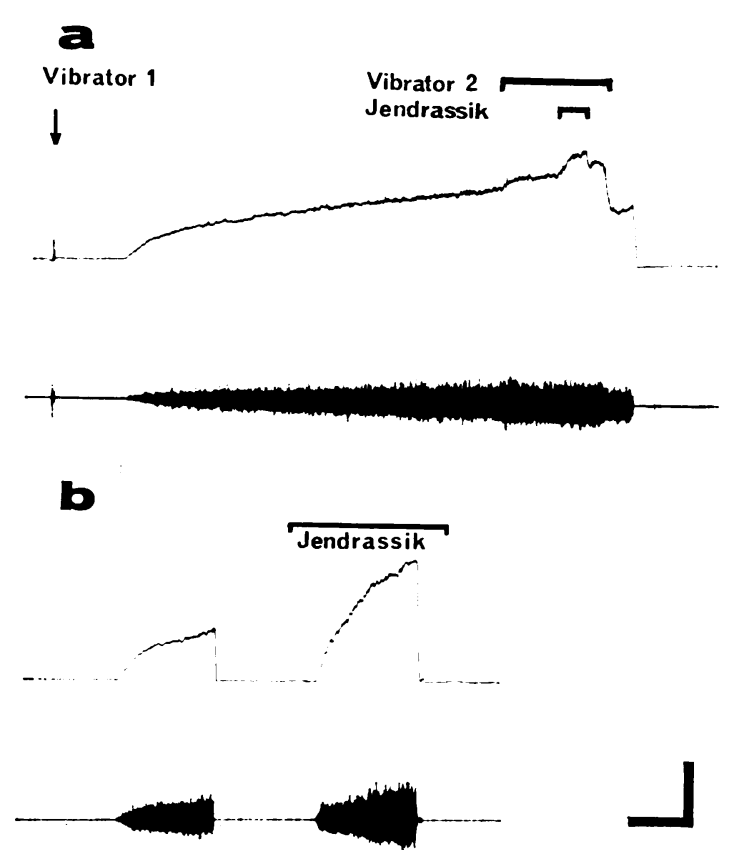

FIG. 2. The TVR of normal man. The tonic contraction develops slowly, taking, in a, more than 60 sec to reach a plateau. In a, the onset of vibration evokes a phasic burst of EMG potentials and a phasic spike of tension. There is then a latent period of $10 \mathrm{sec}$ before the tonic reflex response commences. The tonic contraction is potentiated by the simultaneous use of a second vibrator, and also by reinforcement. In b, reinforcement doubles the size of the tonic contraction. Calibrations: vertical-5 $\mathrm{kg}$ and $1 \mathrm{mV}$; horizontal$10 \mathrm{sec}$.

The tonic contraction was usually quite well maintained, as in spastic patients, and subsided fairly rapidly $0 \cdot 5-2 \cdot 0 \mathrm{sec}$ after vibration ceased. In some tense normal subjects and some tense Parkinsonism patients the onset of vibration was accompanied by a phasic spike of both EMG and tension, similar to that seen in spastic patients. However, reflex tension then subsided almost completely, and the usual incremental tonic contraction started, often after a prolonged latent period (Fig. 2a). As in spastic patients, the latency of the initial spike was 50 to $100 \mathrm{msec}$.

The TVR varied in amplitude from patient to patient in any one group. In two spastic, two normal, and three Parkinsonism patients a TVR could not be recorded unless a Jendrassik manoeuvre was performed and, in these instances, the TVR thus elicited often started with a phasic spike before assuming the pattern 
characteristic of its group. In general the unreinforced TVR was larger in normal subjects $(0$ to $15 \mathrm{~kg})$ than in spastic patients ( 0 to $5 \mathrm{~kg}$ ), but the overlap was considerable. The TVR of patients with Parkinsonism was of intermediate size.

Although it is possible to drive spindle primary endings maximally in the experimental animal (Brown, Engberg, and Matthews, 1967), this does not appear to be possible in man, be he normal, spastic or with Parkinsonism. This was demonstrated by the use of both vibrators simultaneously. During vibration of the patellar tendon at $200 \mathrm{~Hz}$, the resulting tonic contraction could be increased by simultaneous vibration of the muscle belly. Performance of a Jendrassik manoeuvre during such vibration often increased reflex tension even further (Fig. 2a). It thus appears that these vibrators, either individually or in combination, are inadequate to produce a TVR in man which is independent of fusimotor drive.

It was not possible to demonstrate any relationship between variations in the TVR of spastic patients and the type of spasticity or the site of the causative lesion. The exceptions were patients with clinically complete spinal cord lesions, in whom no TVR could be elicited. In hemiplegic spasticity, the TVR was essentially similar to that recorded in patients with spinal lesions, but on the clinically normal side of such patients, the TVR appeared to be of normal configuration.

In five spastic patients clonus could be induced by muscle vibration, and in two normal subjects a phenomenon similar to clonus could be recorded. Clonus only appeared when a phasic spike followed the onset of vibration, and it could be avoided by changing the site or amplitude of vibration, or by increasing the frequency of vibration gradually, so that a phasic spike was not produced. Flexor spasms could be induced by vibration in patients with complete spinal lesions and in four patients with incomplete lesions if the knee were flexed. Anaesthetizing the skin underlying the vibrator with procaine hydrochloride $1 \%$ was sufficient to prevent such spasms in the one patient in whom this was done. In three spastic patients with predominantly extensor hypertonicity vibration provoked extensor spasms when the knee was extended to $30-45^{\circ}$. In two patients with spinal spasticity and grossly exaggerated flexor tone, vibration of the patellar tendon set up a small TVR in the quadriceps muscle at first, but this was interrupted after
2 to $5 \mathrm{sec}$ by a powerful sustained tonic contraction of the hamstrings. This indirect TVR of the hamstrings presumably resulted from spread of vibration to excite the spindle receptors of the hamstrings muscles.

In normal subjects, and to a somewhat lesser extent in patients with Parkinsonism, the TVR could be abolished voluntarily. If vibration was continued and the subject's attention distracted, the TVR resumed its previous level of activity. The ability to suppress the TVR voluntarily of appeared to be impaired in spastic patients, $\frac{\partial}{c}$ particularly those with spinal lesions. Vibration of a paretic muscle potentiated the force produced by voluntary contraction of that muscle, pre- $\triangle$ sumably due to a synergistic effect of reflex $\stackrel{0}{0}$ and voluntary activation of motor units. These $\overrightarrow{0}$ results confirm those of Hagbarth and Eklund (1968). This potentiation of voluntary power did $\vec{\omega}$ not significantly outlast the duration of vibration, although some patients reported that their limbs felt more relaxed and free of spasms for one to $\stackrel{\omega}{\omega}$ two hours after the cessation of vibration, and + they were therefore able to make better use of their paretic muscles. By contrast, vibration did ${ }^{\circ}$ not significantly alter the force of maximal volure tary contraction in normal subjects. The duratio面 of vibration was limited in all subjects by the generation of heat.

EFFECT OF MUSCLE STRETCH ON TVR The effect N of muscle stretch on the quadriceps stretch reflex of spastic patients is seen in Fig. 3. The reflex consists of a dynamic response to the stretching movement, there being little or no response to maintained static stretch. If the amplitude of the $\frac{\varnothing}{\varnothing}$ stretching movement is divided into equal se- $\overrightarrow{\vec{F}}$ quential steps performed at the same velocity $\frac{3}{3}$ of stretch, reflex EMG is maximal in the first step of the movement, but decreases in subse-? quent steps as muscle length increases. In contrast, the quadriceps TVR of spastic patients was found to increase as muscle stretch increases, $\frac{9}{3}$ using similar stepwise stretching movements (Fig. 4). Again the dynamic response to the stretching movement was prominent.

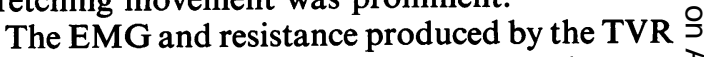
during slow stretching movements became $\frac{D}{0}$ maximal at the position of greatest stretch (Fig. 5a). If the rate of stretching was increased, N peak EMG and peak resistance sometimes led $N$ the position of greatest stretch (Fig. 5b), but this did not produce the clinical sensation of a clasp-knife phenomenon. Since the firing rate 


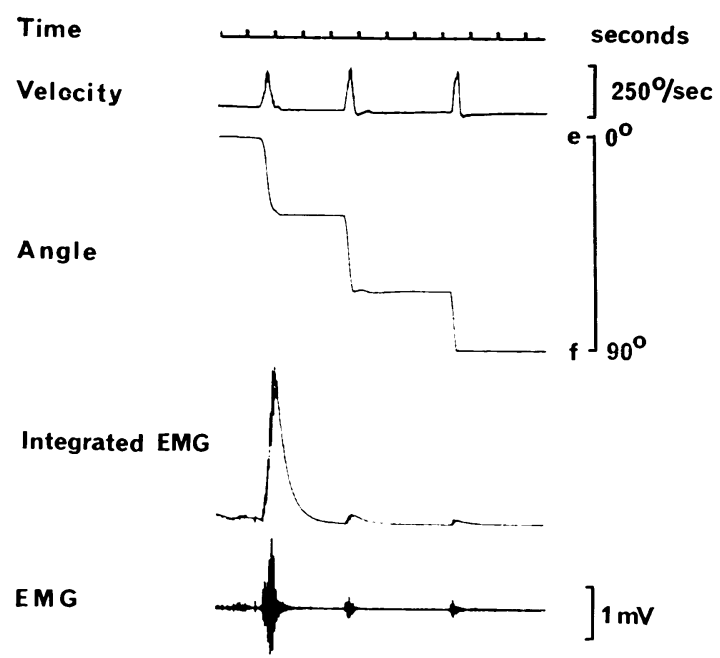

FIG. 3. The effect of muscle stretch on the quadriceps stretch reflex of spastic man. The stretching movement has been divided into three steps of equal amplitude performed at the same velocity of stretch. Reflex EMG is greatest during the first step, and subsequent steps evoke only a small EMG response. Reflex EMG occurs only in response to the stretching movement, and there is no maintained response to static stretch.

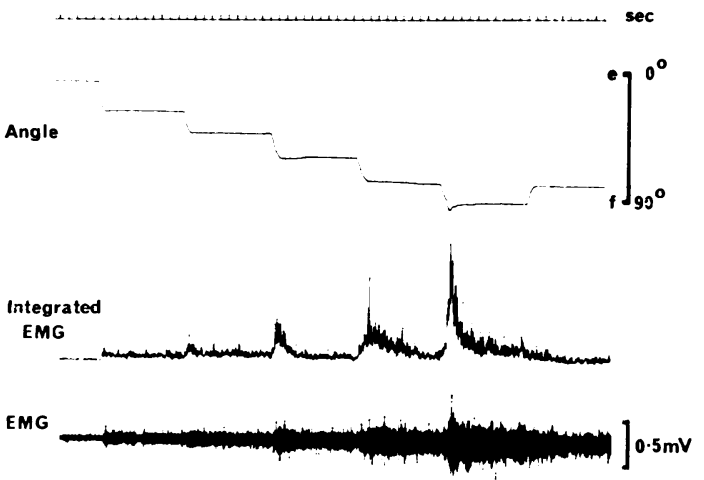

FIG. 4. The effect of muscle stretch on the TVR of spastic man. Vibration of the patellar tendon continues throughout the entire record. Stretch of the quadriceps muscle produced by stepwise flexion movements at the knee joint results in progressive increase in size of the reflex response. There is a prominent dynamic response to the stretching movement.

of the spindle primary ending will increase in response to the velocity of the stretch, these studies do not examine exclusively the effects of changes in muscle length on the TVR. In order to isolate the effects of changes in muscle length uncontaminated by such velocity-dependent factors, the TVR was elicited isometrically at different positions of the knee joint. Again, muscle stretch was found to increase the TVR (Fig. 6). In spastic patients a TVR usually could not be obtained until the knee joint was flexed to 30 to $45^{\circ}$. With further flexion the TVR increased, but the response to increasing length tended to reach a plateau at $90^{\circ}$ flexion.

To demonstrate that this facilitatory effect was an autogenic phenomenon, due to stretch of the vibrated muscle rather than to shortening of the antagonist or activation of joint receptors, the

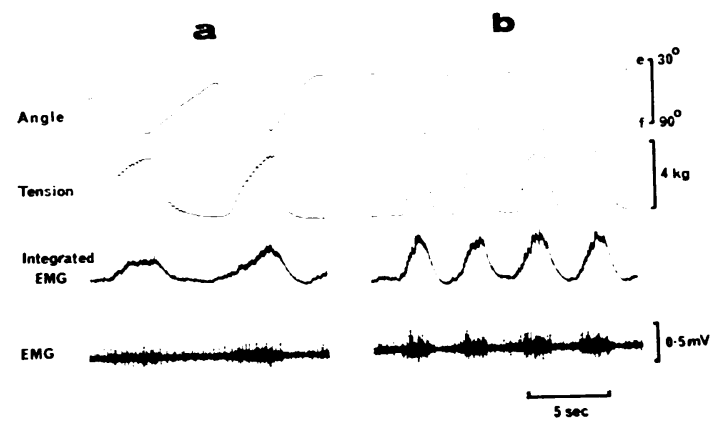

FIG. 5. The effect of the velocity of the stretching movement on the TVR of spastic man. In a, with a slow stretching movement, the reflex response becomes maximal at the position of greatest stretch. In $\mathrm{b}$ with faster stretching movements, reflex EMG and tension peak at a position slightly in advance of the position of greatest stretch. The patellar tendon is being vibrated throughout each record.

quadriceps muscle was stretched by pressure applied to the patella, knee joint position remaining constant. Vibration was applied to the muscle belly above the patella, and the effect on the TVR was recorded by changes in EMG activity. Again, vibration-induced EMG activity increased as the quadriceps muscle was stretched.

Essentially similar results were found when the effect of muscle stretch on the TVR of normal and subjects with Parkinsonism was studied. Usually the TVR increased throughout a stretching movement, but sometimes, especially at faster velocities of stretch, reflex EMG diminished and resistance collapsed as the position of greatest stretch was approached. When the effect of muscle stretch on the TVR was studied under 


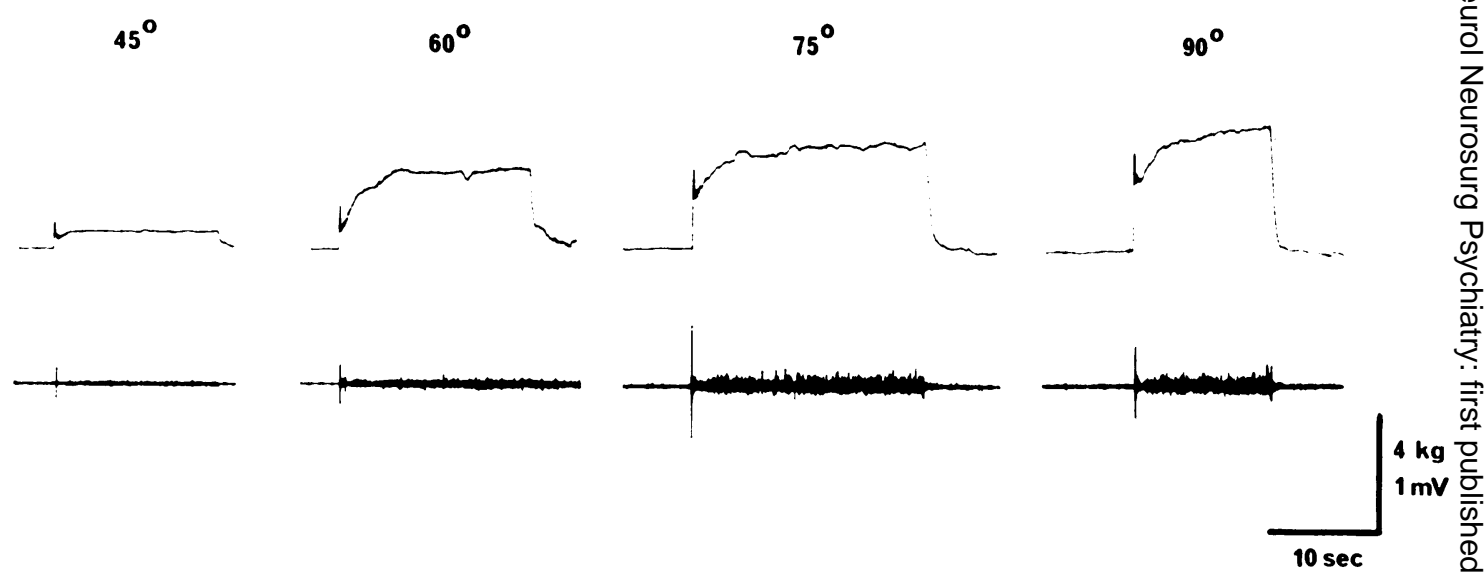

FIG. 6. The effect of muscle stretch on the TVR of spastic man. Increasing muscle stretch increases the size of the $T V R$. The effect tends to plateau between $75^{\circ}$ and $90^{\circ}$.

isometric circumstances, the TVR increased with increasing muscle stretch (Figs 7, 8a), indicating that the apparent inhibition was related to the velocity of the stretching movement rather than to the length of muscle, and was possibly of

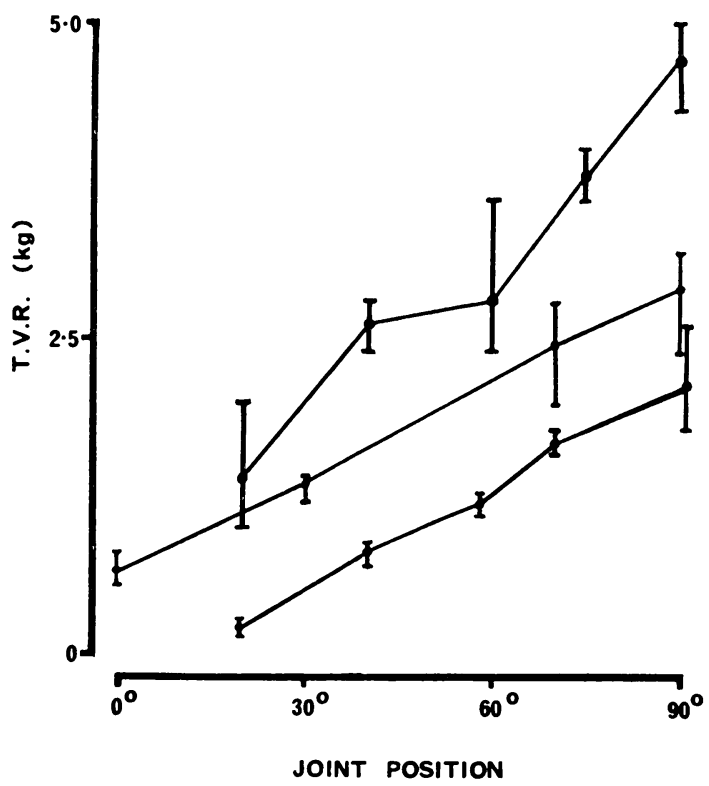

FIG. 7. The effect of muscle stretch on the TVR of patients with Parkinsonism. For each of three patients, increasing muscle stretch increases the size of the resulting TVR, as recorded isometrically. At least three TVRs were obtained for each patient at each joint position, the range being indicated by the vertical lines.

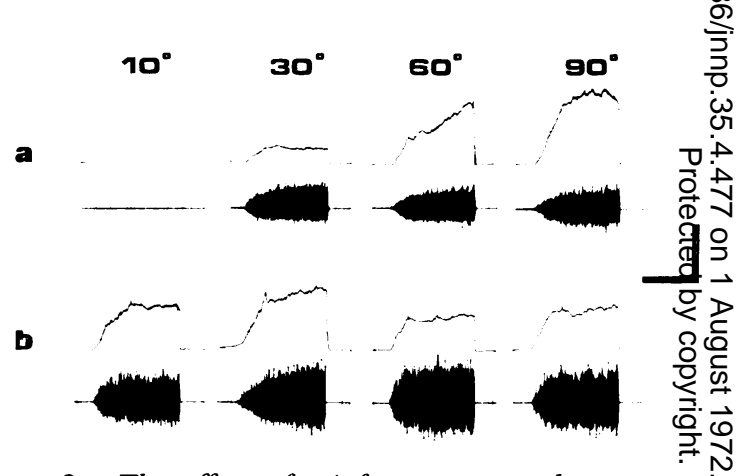

FIG. 8. The effect of reinforcement on the response of the TVR to muscle stretch. In a, the TVR increases as muscle stretch increases. In $\mathrm{b}$, vibration was applied during reinforcement. A large TVR is produced at the $\bar{O}$ position of least stretch and this changes little as the $\frac{\mathrm{O}}{\mathrm{D}}$

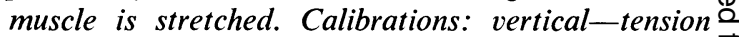
records, $5 \mathrm{~kg}$ for a and first two traces of $\mathrm{b} ; 10 \mathrm{~kg}$ for $\overrightarrow{\overrightarrow{0}}$ last two traces of b. EMG $1 \mathrm{mV}$ for $\mathrm{a}$ and $\mathrm{b}$; horizontal $-20 \mathrm{sec}$.

volitional or supraspinal origin. The effect of $\frac{0}{3}$ muscle stretch on the TVR of normal or Parkinsonism subjects was thus much the same as in spastic patients, except that a TVR could some- 0 times be obtained in normal subjects and those with Parkinsonism when the knee joint was flexed to less than $10^{\circ}$ (Fig. 7).

EFFECT OF REINFORCEMENT ON TVR The effects of 0 reinforcement varied from patient to patient. $\mathcal{W}$ In some normal and some Parkinsonism patients the effect of a Jendrassik manoeuvre was smallo 
and inconstant, but in others a reproducible facilitatory action could be demonstrated when reinforcement was performed before, during or throughout vibration (Fig. 2). Similar results were obtained in spastic patients, reinforcement having no significant effect in some patients, but consistently increasing the force generated by the TVR in others (Fig. 9a). In normal, Parkinsonism, and spastic patients the effects of the Jendrassik manoeuvre significantly outlasted the duration of the manoeuvre (Fig. 9a). The duration of this facilitation was studied by performing the manoeuvre at variable intervals before the onset of vibration. The greatest facilitation occurred if vibration started within $0.5 \mathrm{sec}$ of the cessation of the manoeuvre, but some potentiation persisted for as long as 10 sec (Fig. 9b).
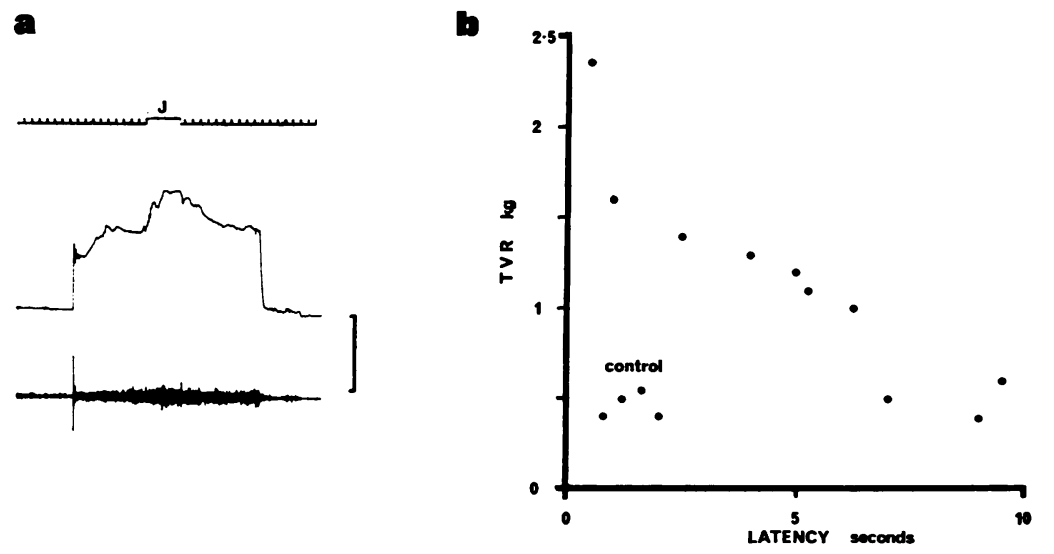

If the Jendrassik manoeuvre started before the onset of vibration a phasic contraction could be induced in some normal and some Parkinsonism subjects, and also in some spastic patients in whom a phasic spike had not previously been recorded. In normal and Parkinsonism subjects tension and EMG subsided after the phasic spike and the usual incremental TVR then ensued. In spastic patients tension and EMG decreased only slightly before rapidly climbing to the plateau level.

The degree of potentiation of the TVR produced by reinforcement at different joint positions was studied in order to determine the degree of interaction of these facilitatory influences. The amount by which the TVR could be potentiated by a Jendrassik manoeuvre was greatest when muscle stretch was least, and was least when muscle stretch was greatest (Fig. 8). When evoked during reinforcement, increasing muscle stretch had less effect on the TVR, so that the TVR varied little from one joint position to the next (Fig. 8b). It thus appeared that at less stretched positions reinforcement was capable of compensating for the degree of muscle stretch.

\section{DISCUSSION}

Significant differences have been demonstrated between the TVR of spastic patients and that of normal or Parkinsonism subjects. Although

FIG. 9. The duration of the potentiation of the TVR produced by reinforcement. In a, a Jendrassik manoeuvre $(J)$, performed during muscle vibration, potentiates the $T V R$. The potentiation outlasts the manoeuvre. In b, the effect of a Jendrassik manoeuvre conditioning a subsequent TVR is shown. The effect is maximal immediately after the cessation of the manoeuvre, but some potentiation persists for as long as 10 sec. Calibrations for a-vertical $2 \mathrm{~kg}$ and $1 \mathrm{mV}$; time marker, 1 sec/division. variations in the speed of onset of the TVR were recorded in each group, it is apparent that the rapidly developing TVR is characteristic of spasticity, while that of normal man or patients with Parkinsonism develops relatively slowly. In some normal subjects the onset of the TVR became more rapid if the frequency of vibration was increased, and in some spastic patients a slowly increasing tonic contraction could be evoked by reducing the frequency or changing the site of vibration. As pointed out by Hagbarth and Eklund (1968), the TVR of spasticity usually resembles that found in the decerebrate or anaesthetized cat (Matthews, 1966; Gillies et al., 
1971a, 1971b). When low frequency vibration was applied to the non-denervated limb of anaesthetized cats, Gillies et al. (1971a) were able to record the slowly progressive increase in EMG and reflex tension characteristic of the TVR of normal man. They concluded that the difference in time course of the TVR of the decerebrate animal and that of normal man was related to the innervation of the limb other than that of the muscle vibrated. However, this conclusion does not explain the differences in the TVR of normal and spastic man and it is probable that, given a comparable vibration stimulus, the spastic TVR differs significantly from the normal TVR.

At the outset of this study it was hoped that consistent differences in the TVR might be found in spasticity of different aetiologies, such that a gradation between the normal TVR and the spastic TVR could be demonstrated. No such difference could be found. The variation encountered in any one subject was so great that no single pattern could be regarded as specific for any particular form of spasticity. The similarity of the normal and Parkinsonism TVR and their identical response to muscle stretch suggest that spinal reflex mechanisms are normal in Parkinson's disease. This conclusion supports the postulate of Landau (1969) that rigidity of Parkinsonism arises from increased supraspinal drive of essentially normal segmental mechanisms.

An initial burst of EMG resulting in a phasic rise in tension followed the onset of vibration in many spastic patients, and in some normal or Parkinsonism subjects during reinforcement. The latency of this burst of EMG was such that it can be attributed only to a spinal reflex. The height of the resulting phasic spike of tension (cf Figs 1, 6, 9a) suggest synchronous firing of motoneurones, and it is probable that this phasic response is a vibration-induced tendon jerk. That the latency of the response could be as long as $100 \mathrm{msec}$ probably arises from the inertia of the vibrator when first applied to the limb, and temporal summation at motoneurone level of the afferent activity from the initial strokes of the vibrator.

The phasic spike was followed by a brief pause in EMG activity of 100 to $150 \mathrm{msec}$. This silent period may be accounted for by unloading of the muscle spindle by the initial phasic contraction and by autogenic inhibition from Golgi tendon organs activated by it. If most moto- neurones were activated in the phasic contraction there would be a tendency for these motoneurones $\bar{z}$ to fire synchronously when activity resumed after $\stackrel{0}{\leftarrow}$ the silent period. It is thus not surprising that vibration may initiate clonus in spastic patients and in some normal subjects. Since the silent 0 period is probably determined by the occurrence ${ }^{\infty}$ of a phasic response to the onset of vibration, $?$ it might be expected that the presence of clonus would be correlated with the presence of $a$ phasic contraction, and that efforts to avoid this $\overrightarrow{\vec{s}}$ phasic contraction would also prevent clonus.

Muscle stretch enhanced the TVR in normal, Parkinsonism, and spastic man. Presumably this $\stackrel{\vec{s}}{\overrightarrow{2}}$

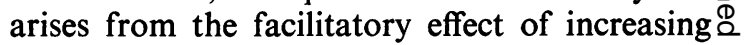
muscle length on the response of the spindle $\%$ primary ending to vibration (Brown et al., 1967), $\vec{\circ}$ since recordings of afferent fibre activity in man $\overrightarrow{.}$ have shown that muscle stretch increases the $\vec{\rho}_{\mathcal{O}}$ group Ia response to vibration (Hagbarth and $\overline{\widehat{F}}$. Vallbo, 1967, 1968). In the cat a TVR cannot beo elicited in a slack muscle, and does not become $\omega_{\mathrm{w}}^{\omega}$ maximal until the vibrated muscle is stretched to + its maximal physiological length, producing $\vec{q}$ passive tension of up to $200 \mathrm{~g}$ (Matthews, $196 \%$ Gillies et al., 1971a). A similar situation appea\&s to exist in spastic man in whom the quadrice TVR usually cannot be elicited until the kneeco joint is flexed to $30-45^{\circ}$. In normal man and क्ञ patients with Parkinsonism the threshold leng $\overrightarrow{1} \overrightarrow{0}$ at which a TVR can be elicited appears to be N less, but otherwise the response to increasing muscle length is qualitatively the same.

In spastic man the quadriceps stretch reflex decreases as muscle length increases, an effect probably due to autogenic inhibition from the $\stackrel{\circ}{\circ}$ spindle secondary ending (Burke et al., 1970). $\overrightarrow{\vec{P}}$ However the secondary ending is insensitive 3 to muscle vibration (Brown et al., 1967). It is probable then that in spasticity the quadriceps? TVR increases as muscle length increases because $\bar{\Xi}$ stretch enhances the primary ending's response? to vibration but does not alter the slight response $\frac{0}{3}$ of the secondary endings to vibration. The inhibitory effects of the secondary ending in- $\frac{\mathrm{O}}{3}$ crease in proportion to increasing muscle length, but presumably this is masked by the greater 5 response of the primary ending to vibration. It is apparent then that the TVR cannot be equated with the tonic stretch reflex, at least in ज spasticity.

Potentiation of the TVR by reinforcement was స్ట not found in all subjects, but when present ito was usually reproducible. In all spastic patients, 
including those spinal patients in whom reinforcement potentiated the TVR, a prominent claspknife phenomenon could be elicited in the quadriceps stretch reflex. It has been suggested that the clasp-knife phenomenon in cases of spinal spasticity results from release of the group II afferent pathway due to a lesion of the posterolateral funiculus of the spinal cord (Burke, Knowles, Andrews, and Ashby, 1972). In these circumstances it is therefore likely that the descending pathways mediating the facilitatory effects of reinforcement traverse the anterior quadrant of the spinal cord.

The duration of the potentiation induced by reinforcement outlasted the reinforcing manoeuvre by up to $10 \mathrm{sec}$. In contrast to the effects on alpha motoneurones, reflex or supraspinal activation of gamma motoneurones evokes high frequency repetitive firing, thus producing effects which may long outlast the stimulus (Hunt and Paintal, 1958). The long duration of the potentiation induced by reinforcement in man is therefore consistent with activation of the fusimotor system, in addition to any direct action on the alpha motoneurone. The suggestion that reinforcement acts at least partially through the fusimotor system is supported by the finding of interaction between the effects of the Jendrassik manoeuvre and those of muscle stretch. Reinforcement was most conspicuous when the muscle was in the shortened position, and became proportionately less as stretch increased. This suggests that stretch and reinforcement use a common path to produce their effects on the TVR. Thus reinforcement probably acts at least in part through the fusimotor system, setting the contraction of intrafusal fibres at a level which compensates for the length of extrafusal fibres. The demonstration of an effect on the gamma efferent system does not exclude a parallel effect on the alpha motoneurone in addition. In man, Hagbarth and Vallbo (1968, 1969) and Hagbarth, Hongell, and Wallin (1970) have demonstrated coactivation of alpha and gamma motoneurones during voluntary contraction of muscle, and it is therefore to be expected that reinforcement would also activate both types of motoneurone.

The authors would like to thank Dr. J. D. Gillies and Miss Lyndsay Knowles for assistance with some of the experiments reported here. $\mathrm{Mr} \mathrm{K}$. Norcross and Mr N. Skuse have given valuable technical aid. The financial assistance of the National Health and Medical Research Council of Australia, the Adolph Basser Trust, and $\mathrm{Mr}$ and Mrs Edwin Street is gratefully acknowledged. Illustrations were photographed by the Department of Medical Illustration, University of New South Wales.

\section{REFERENCES}

Ashby, P., and Burke, D. (1971). Stretch reflexes in the upper limb of spastic man. Journal of Neurology, Neurosurgery, and Psychiatry, 34, 765-771.

Brown, M. C., Engberg, I., and Matthews, P. B. C. (1967). The relative sensitivity to vibration of muscle receptors of the cat. Journal of Physiology, 192, 773-800.

Burke, D., Andrews, C., and Ashby, P. (1971). Autogenic effects of static muscle stretch in spastic man. Archives of Neurology. 25, 367-372.

Burke, D., Gillies, J. D., and Lance, J. W. (1970). The quadriceps stretch reflex in human spasticity. Journal of Neurosurgery, and Psychiatry, 33, 216-223.

Burke, D., Gillies, J. D., and Lance, J. W. (1971). Hamstrings stretch reflex in human spasticity. Journal of Neurology, Neurosurgery, and Psychiatry, 34, 231-235.

Burke, D., Knowles, L., Andrews, C., and Ashby, P. (1972). Spasticity, decerebrate rigidity and the clasp-knife phenomenon: an experimental study in the cat. Brain. (In press.)

De Gail, P., Lance, J. W., and Neilson, P. D. (1966). Differential effects on tonic and phasic reflex mechanisms produced by vibration of muscles in man. Journal of Neurology, Neurosurgery, and Psychiatry, 29, 1-11.

Eklund, G., and Hagbarth, K.-E. (1965). Motor effects of vibratory muscle stimuli in man. (Abstract.) Electroencephalography and Clinical Neurophysiology, 19, 619.

Eklund, G., and Hagbarth, K.-E. (1966). Normal variability of tonic vibration reflexes in man. Experimental Neurology, 16, 80-92.

Gillies, J. D., Burke, D. J., and Lance, J. W. (1971a). Tonic vibration reflex in the cat. Journal of Neurophysiology, 34, 252-262.

Gillies, J. D., Burke, D. J., and Lance, J. W. (1971b). Supraspinal control of tonic vibration reflex. Journal of Neurophysiology, 34, 302-309.

Hagbarth, K.-E., and Eklund, G. (1966a). Motor effects of vibratory muscle stimuli in man. In Muscular Afferents and Motor Control. Proceedings of the First Nobel Symposium Held in June 1965 at Södergarn on the Island of Lidingö in the County of Stockholm. pp. 177-186. Edited by R. Granit. Almqvist and Wiksell: Stockholm.

Hagbarth, K.-E., and Eklund, G. (1966b). Tonic vibration reflexes (TVR) in spasticity. Brain Research, 2, 201-203.

Hagbarth, K-E., and Eklund, G. (1968). The effects of muscle vibration in spasticity, rigidity, and cerebellar disorders. Journal of Neurology, Neurosurgery, and Psychiatry, 31, 207-213.

Hagbarth, K.-E., Hongell, A., and Wallin, B. G. (1970). The effect of gamma fibre block on afferent muscle nerve activity during voluntary contractions. Acta Physiologica Scandinavica, 79, 27A-28A.

Hagbarth, K.-E., and Vallbo, A. B. (1967). Afferent response to mechanical stimulation of muscle receptors in man. Acta Societatis Medicorum Upsaliensis, 72, 102-104.

Hagbarth, K.-E., and Vallbc, Å. B. (1968). Discharge characteristics of human muscle afferents during muscle stretch and contraction. Experimental Neurology, 22, 674-694.

Hagbarth, K.-E., and Vallbo, $\AA$. B. (1969). Single unit recordings from muscle nerves in human subjects. Acta Physiologica Scandinavica, 76, 321-334.

Hunt, C. C., and Paintal, A. S. (1958). Spinal reflex regulation of fusimotor neurones. Journal of Physiology, 143, 195-212.

Lance, J. W. (1965). The mechanism of reflex irradiation. Proceedings of the Australian Association of Neurologists, 3, 77-81. 
Lance, J. W., De Gail, P., and Neilson, P. D. (1966). Tonic and phasic spinal cord mechanisms in man. Journal of Neurology, Neurosurgery, and Psychiatry, 29, 535-544.

Landau, W. M. (1969). Spasticity and rigidity. In Recent Advances in Neurology, pp. 1-32. Edited by F. Plum. Davis: Philadelphia.

Marsden, C. D., Meadows, J. C., and Hodgson, H. J. F. (1969). Observations on the reflex response to muscle vibration in man and its voluntary control. Brain, 92, 829-846.
Matthews, P. B. C. (1966). The reflex excitation of the soleus muscle of the decerebrate cat caused by vibration applied $\underline{0}$ to its tendon. Journal of Physiology, 184, 450-472.

Matthews, P. B. C. (1969). Evidence that the secondary as $\mathbb{D}$ well as the primary endings of the muscle spindles may be responsible for the tonic stretch reflex of the decerebrate cat. Journal of Physiology, 204, 365-393.

Rushworth, G., and Young, R. R. (1966). The effect of vibration on tonic and phasic reflexes in man. Journal of Physiology, 185, 63P-64P. 